\title{
Case Reports Are the Starting Point to Medical Science
}

\author{
Toshio Hattori $(\mathbb{D}$
}

Department of Health Science and Social Welfare, Kibi International University, 8 Igamachi, Takahashi 716-8508, Japan; hattorit@kiui.ac.jp

Received: 25 March 2020; Accepted: 27 March 2020; Published: 1 April 2020

I am serving as the Editor-in-Chief of an OPEN ACCESS medical journal Reports published by MDPI (Indexed by DOAJ and CLOCKSS, http://www.mdpi.com/journal/reports).

I would like to invite you to publish a case report or other related article, for peer-review and possible publication in Reports. We will process your submission as the feature paper with priority and the publication fees will be enjoy a $* 50 \%$ reduction* within 2020 . (submissions before 1 st July would be fully waived).

Reports is a new open access medical journal that publishes case reports and other related articles. Our aim is to improve the management of patients by compiling reports across all medical disciplines that are both practical and useful for clinicians, researchers, healthcare professionals, and other relevant care providers. You may find the details at http://www.mdpi.com/journal/reports/about.

In 2019, Prof. Dr. Jesús Devesa and Dr. Geoffrey Brown joined as the Editor-in-Chief. Twenty-eight papers were published and the average publication time was 33.5 days. The corresponding authors of papers published in 2019 came from 17 different countries, while in 2018, the number was 10.

The number of full-text views in 2019 was 33,620, which is almost 3.5 times more than that in 2018. Three Special Issues are open for submission now as follows "Case Reports in Oncology", "Does Atherosclerosis Begin in Childhood?" and "Childhood Obesity: New knowledge, Cases and Interventions". The effect on publication in open journal is immense and my published works were printed 3000 times and I received a requesting mail for international collaboration. To improve the quality, we are planning to increase the numbers of the reviewer board and the winner of the first Reports Travel Award 2020 was announced at https://www.mdpi.com/journal/reports/awards.

It is needless to state the importance of case reports, because it is a manifestation of the mind that clinicians seek to observe patients scientifically. Therefore, writing a clinical report is the best educational tool for clinical management. It is also important to describe detailed clinical symptoms as they are, but it is also important to take a step forward and experiment with no one tried. Owing to the efforts, a new clinical entity such as human retrovirus-induced diseases (adult $\mathrm{T}$ cell leukemia, acquired immune deficiency syndrome) emerged from the reports of unique clinical findings of the patients.

We are also facing a disaster era due to global warming. There are various disaster-related diseases which we have suffered from ancient days [1]. It is needless to say that the Covid-19 pandemic is a disaster itself. We also welcome your experience on your important case reports on disaster-related diseases.

We sincerely appreciate your supporting for our journal Reports.

If you have any questions, please contact me, or the Reports Editorial Office (reports@mdpi.com).

Thank you very much for your consideration. We would be glad to receive a contribution from you and we look forward to hearing from you soon.

Best regards,

Prof. Toshio Hattori 


\section{Reference}

1. Bai, G.; Niki, T.; Kikuchi, H.; Sumi, A.; Kobayashi, N.; Haruyama, T.; Zhang, J.; Chagan-Yasutan, H.; Hattori, T. New Development of Disaster-Related and Tropical Infectious Diseases Control. Reports 2020, 3, 5. [CrossRef]

(c)

(C) 2020 by the author. Licensee MDPI, Basel, Switzerland. This article is an open access article distributed under the terms and conditions of the Creative Commons Attribution (CC BY) license (http://creativecommons.org/licenses/by/4.0/). 